\title{
MODELING OF PUMPING COLD DEEP NUTRIENT-RICH SEAWATER FOR MARICULTURE AND NUCLEAR POWER PLANT COOLING APPLICATIONS
}

\author{
B. J. Huano \\ Department of Mechanical Engineering, National Taiwan University, Taipei, Taiwan, Republic of China

\begin{abstract}
Abatruet-A simple theoretical model is developed to abess the tecthnical feasibility of pumping cold deop nutrient-rich seawater for mariculture and nuclear power plent cooling. Simulations for two locations in eastern Taiwan have shown that replacing warm curface conweter by cold deep ceawater as nuclear power plant coolant is technically feasible for pipes with diumeters lareer than $150 \mathrm{~cm}$ and intake levels deeper than $400 \mathrm{~m}$. The grevitational forcoinduced flow system is aleo eramined and shown not to be suitable for the nuclear power phant coolins application. However, it is shown that both syatems are sultable for mericulture applications. The required pumpins powers at difierent pipeline conditions are sleo presented in the paper, for decien purposes.
\end{abstract}

\section{NOMENCLATURE}

\begin{tabular}{|c|}
\hline 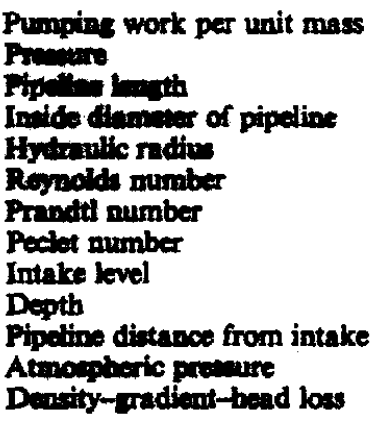 \\
\hline
\end{tabular}

$\dot{W}$ Pumpins power to the ceawater flow in the pipe

C) Spovific beat of wew water

U Overall beat tramefer coefficient

T. Tempenture distribution of seawater

$T_{\infty} \quad$ Senwater temperature at infinite depth.

$\dot{W}_{\mathrm{met}} \quad$ Net power output of original power cycle

$r$

Heat added to the boiler of the power plant

Surface sawater tempersturo

Deep soawater temperature at the outlet of the pipeline

Now condenation temperature of the power plant

New power output

Net power gain due to deep cold seawater cooling

Ground hole depth

Fluid kinematic viscodity indide the pipe

Oravitational acceleration

Gravitational beight

Fluid density 


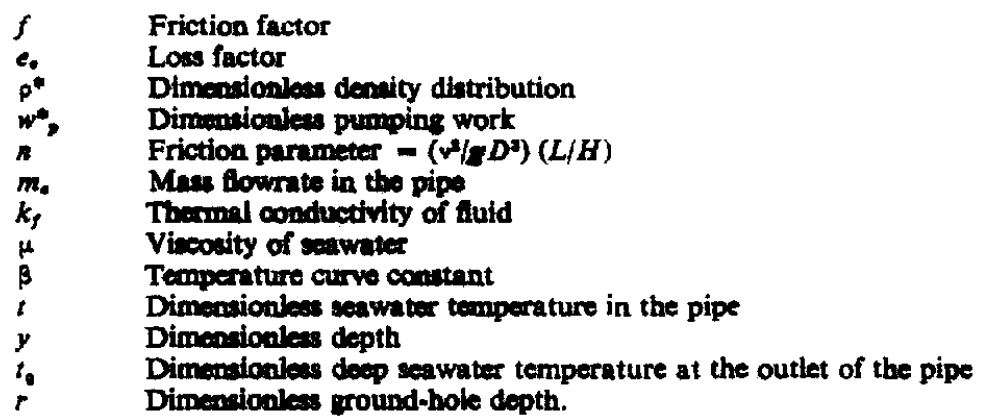

\section{INTRODUCTION}

THE IDEA of uning the temperature difieneace between the warm aurfuce wates of the tropieal oceans and the doep cold layer returniag from the arctic regions to run a Retine-oycle heat encine to genorate electricity was firt proposed by d'Arconval in I891 and was firt

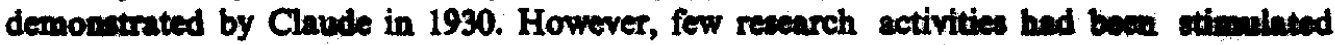

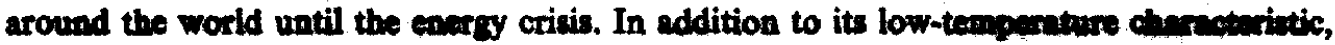
coen deep water is the largest nutrient reservoir for marine life. Wasmed sulwates coming from a depth below $700 \mathrm{~m}$ could be used for the growth of algae, shellinh, cruatean, and seaweed. The growth rate has been proved to be much fatter than in nature (Othan and Roels, 1974). An experimental station has been in operation on the north const of St Croix, one of the U.S. Virgin Islands, near Puerto Rico (Othmar and Roels, 1970). Thave

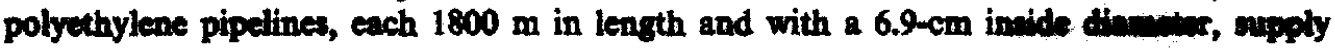
water from an $870-\mathrm{m}$ depth at a rate of $1501 / \mathrm{min}$. This water is waned by baing down up through the sunll pipes, so that it is satisfactory for mariculture apliation. One of the

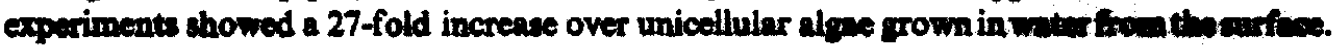
Coniderably rapid growth is also found for clams, European oytar, by silloge, and lobuters etc.

The combined applications utilizing cold deep seawnter were proponad by Othnar (1976). He sureated a number of engineering alternative whish frat un the cold dowp seawnter for the OTEC system and then use the waste seawater to grow mafoods.

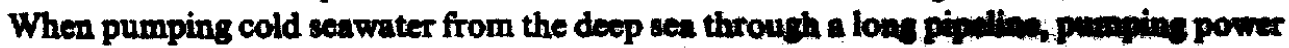
is consumed in overcoming the flow friction loss and the denity-andinandend low. The latter results from the density difierence between the ceaswator in the pipe and the seawater outside the pipe, because all the water in the pipe is approxinatily at the denity of the intake level whereas the density of the water outuide the pipe decinese all the way to the sea surface. On the other hand, when drawing cold senwerter from the comen depths through the warmer water up to the surface, the cold cenwater will be wariad and the temperature rise will have a large impact on system performance. A great doal of theoretical work has been performed recently to study the teahinieal and economien feasibility of extracting cold deep seawnter for power generntion (Grimin, 1975; Watt et al., 1977; Zener, 1977). However, little has been mentionod in deteil sbout the enpinening aspects of pumping cold deep seawater for OTEC, marieulture or othes revilintions.

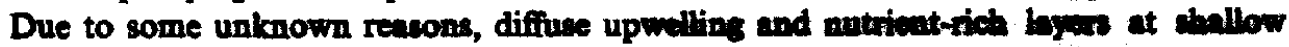

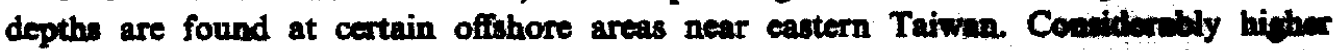
nutrient content is expected at deeper layers. Water in these layers can be punpod up to the 
seashore for mariculture applications after exposure to the atmosphere for oxygen saturation and warming. The low-temperature nature of the deep seawater can also l e used for nuclear power plant cooling, to promote thermal efficiency or for OTEC applications. To understand this, a simple analytical model for a straight pipeline stretched directly from the seashore into the deep-sea region has to be developed to evaluate the pumping power for drawing deep seawater up to shore and the temperature rise due to warming-up during pumping, as well as the resultant effect on the feasibility of nuclear power plant cooling (see Fig. 1). To reduce the maintenance problem of the pumping facilities, a recond kind of piping arrangement is proposed and examined. This pipeline is similar to the first kind except that the outlet of the pipeline is open to a deep ground-hole at the seashore, so as to maintain an elevation between the sea surface and the outlet of the pipeline and thus induce a gravitational driving force to draw up deep seawater. It is apparent that the induced flowrate will be a function of pipeline diameter, intake level, and elevation difference between the pipeline outlet and the sea surface. The calculation results presented in the present paper can be used for design purposes. For nuclear power plant cooling applications, a simulation will be carried out for a nuclear power plant at the two locations on the eastern coast of Taiwan to study the engineering feasibility of replacing the warm surface seawater coolant by cold deep seawater.

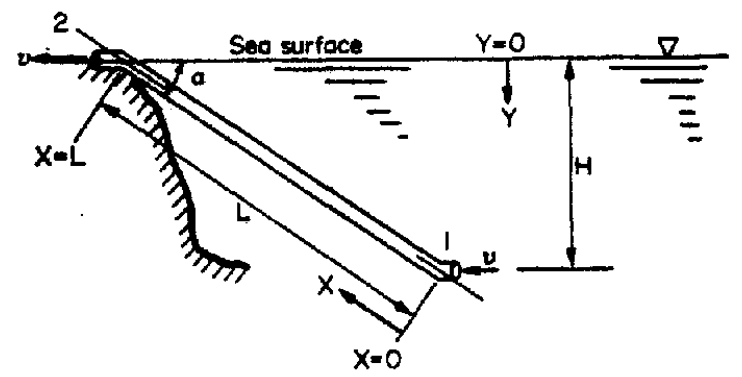

FrG. 1. Basic pipeline configuration.

\section{PUMPING DEEP SEAWATER THROUGH PIPELINE}

The basic pipeline model considered in the present analysis is shown schematically in Fig. 1. For steady incompressible fluid flow through a pipeline, the Bernoulli equation can be used to deal with the momentum balance:

$\Delta\left(v^{3} / 2\right)+g \Delta h+\int_{1}^{2} \mathrm{~d} P / \rho-W_{p}+\sum_{i}\left[f\left(L / R_{h}\right) v^{2} / 2\right]_{i}+\sum_{l}\left(e_{v} v^{2} / 2\right)_{i}=0$,

where $v$ is the average velocity of the fluid inside the pipe, $h$ is the gravitational height, $P$ is the fluid pressure, $\rho$ is the fluid density inside the pipe, $W_{p}$ is the pumping work to the fluid per unit mass, $g$ is the gravitational acceleration and $L$ is the pipe length. The fifth term of (1) represents the sum of all sections of the pipeline. $f$ is the friction factor depending on the Reynolds number and can be expressed for smooth pipes as, according to Moody (1944), 


$$
f= \begin{cases}16 / \operatorname{Re} & \operatorname{Re}<2100 \\ 0.0791 / \operatorname{Re}^{0.2 s} & 2100<\operatorname{Re}<20,000 \\ 0.046 / \operatorname{Re}^{0.8} & 20,000<\operatorname{Re}<10^{7}\end{cases}
$$

where $\operatorname{Re}$ is defined as $v D / v, D$ is the inside diameter of the pipe and $v$ is the kinematic viscosity of the fluid. $R_{h}$ in (1) is the mean hydraulic radius. For a circular pipe, $R_{h}=D / 4$. $e_{v}$ is the loss factor due to fittings, valves, and bends etc.

To simplify the analysis, the following assumptions are made:

(1) Seawater is incompressible. The cross-section of the pipeline is uniform and the pipe is straight all the way from the seashore down to the offshore deep sea region, as shown in Fig. 1. Therefore the average velocities of the seawater at the intake and at the outiet of the pipeline are same, i.e. $\Delta_{v}=0$, and the loss factor can be ignored, i.e. $e_{y}=0$.

(2) The seawater in the pipeline is all at the density of the intake level. Therefore, $\rho_{1}=\rho \Delta=\rho_{H}=$ constant, and

$$
\int_{1}^{2} \mathrm{~d} P / \rho=\left(P_{2}-P_{1}\right) / \rho_{H} .
$$

(3) The outlet of the pipe is at sea level, and the pipe is circular.

(4) Only one straight pipe is considered in the present analysis, so that

$$
\sum_{l}\left[f\left(L / R_{h}\right) v^{2} / 2\right]_{l}=f\left(L / R_{h}\right) v^{2} / 2 .
$$

From above assumptions, (1) can be written as:

$$
W_{p}=g H+\left(P_{8}-P_{1}\right) / \rho_{H}+f\left(L / R_{h}\right) v^{\mathbf{s}} / 2
$$

Since the seawater is pumped into the atmosphere at the outlet, the outlet pressure $P_{1}$ is equal to the ambient pressure $P_{a}$, i.e. $P_{2}=P_{a}$. Thus the intake presoure $P_{1}$ can be evaluated by the hydrostatic relation:

$$
P_{1}=P_{2}+\int_{0}^{H} \rho g \mathrm{~d} Y=P_{2}+\int_{0}^{H} \rho g \mathrm{~d} Y,
$$

where $\rho$ is the seawater density distribution with respect to depth outside the pipe. $Y$ represents the depth from sea surface. Subatituting (6) into (5), we get

$$
W_{p}=8 H-\int_{0}^{H}\left(\rho / \rho_{A}\right) d Y+f\left(L / R_{h}\right) y^{8} / 2 .
$$


Normalization of $(7)$ yields

$$
w_{p}^{*}=1-\int_{0}^{1} \rho^{*} \mathrm{~d} y+\left(v^{2} / 2 g\right)(L / H) f / R_{h},
$$

where

$$
w_{p}^{*} \equiv W_{p} / g H, y \equiv Y / H \text { and } \rho^{*}(y) \equiv \rho(Y) / \rho_{H}
$$

Also we define a new parameter $Z$ as $Z=1-\int_{0} p^{*}$ dy. Here $Z$ represents the densitygradient-head loss depending on the density distribution. Since there exists thermohaline circulation at deep sea region, the variation of density with depth is generally not so smooth that a single profile $\rho(Y)$ can be approximated. Therefore, instead of direct integration, a finite difference summation is used to calculate the density-gradient-head loss, i.e.

$$
Z=1-\Sigma_{i} \dot{\rho}_{i}^{*} \Delta y_{i}
$$

where $\bar{\rho}_{i}^{*}=\left(\rho_{i}^{*}+\rho_{i-1}^{*}\right) / 2$, and $\Delta y_{i}=y_{i}-y_{i-1}, i=1,2, \ldots$ Since the density distributions are different in different oceans and in different seasons, $Z$ is actually a regional and seasonal function determined from measurements. Substituting (2) for friction factor $f$ into (8), we obtain

$$
w_{p}^{*}= \begin{cases}Z+32 n \operatorname{Re}, & \operatorname{Re}<2100 \\ Z+0.1582 n \operatorname{Re}^{7 / 4}, & 2100<\operatorname{Re}<20,000 \\ Z+0.092 n \operatorname{Re}^{9 / 5}, & 20,000<\operatorname{Re}<10^{7}\end{cases}
$$

where $n=\left(\Delta^{2} / g D^{\prime}\right)(L / H)$. Equation (10) shows that the required pumping work to the fluid is a function of $Z, n$, and Re as plotted in Fig. 2. And, $n$ is a factor depending on the viscosity of seawater and the geometry of the pipeline.

The variation of Z-values on the eastern coast of Taiwan ranges from 0.001 to 0.002 for depths down to $1000 \mathrm{~m}$. This is small, but cannot be arbitrarily ignored. If the flowrate is very small, such as in mariculture applications, $Z$ becomes dominant. For a high flowrate such as in nuclear power plant cooling applications, it may be neglected compared with the frictional loss.

From (10), the total pumping power $\dot{W}_{p}$ for a given mass flowrate of deep ceawater $m_{c}$ from depth $H$ can be evaluated by the relation:

$$
\dot{W}_{p}=m_{c} g H w_{p}^{*}
$$

\section{HEATING LOSS DURING PUMPING}

When pumping the cold deep seawater through the pipeline, the water will be warmed due to heating through the pipe wall by the warmer outside seawater. A simple analytical model will be developed to predict the thermal loss. 


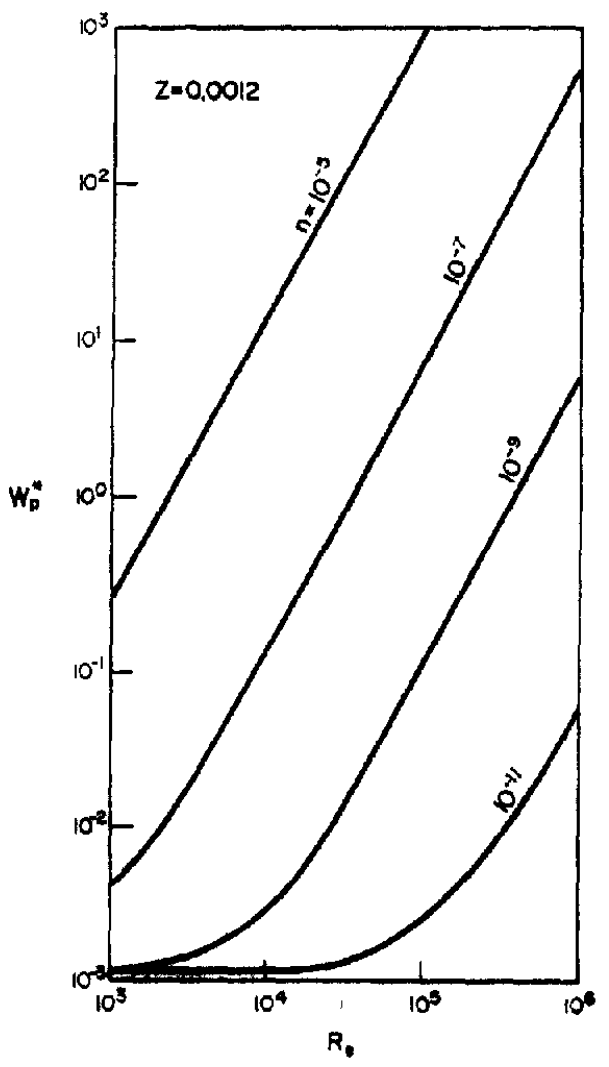

FIG. 2. Pumping work vs Reynolds number.

By energy balance to a differential volume of seawater inside the pipe $d \boldsymbol{L}$, the following equation can be derived:

$$
m_{c} C_{p} \mathrm{~d} T=U \pi D\left(T_{s}-T\right) \mathrm{d} L,
$$

where $C_{p}$ is the specific heat of seawater, $T$ is the mean bulk seawater temperature at $L$, $U$ is the overall heat transfer coefficient across the pipe wall, $T_{z}$ is the temperature diatribution of seawater with respect to depth, and $L$ is the position of the intake. From Fig. I, the transformation of the coordinate yields

$$
\mathrm{d} L=-(L / H) \mathrm{d} Y .
$$

Substituting (13) into (12) and rearranging, we obtain

$$
\frac{\mathrm{d} T}{\mathrm{~d} Y}=-\frac{4 L}{k_{f} \operatorname{PrRe}}\left(\frac{L}{H}\right)\left[T_{s}(Y)-T(Y)\right],
$$


where $k_{f}$ is the thermal conductivity of seawater inside the pipe, $\operatorname{Pr}\left(\equiv \mu_{f} C_{d} / k_{f}\right)$ is the Prandtl number of the seawater. Equation (14) can be solved if the temperature distribution of seawater, $T_{r}(Y)$, known.

In many oceans, the temperature variations with depth are so smooth that an exponential function (15), can be used to fit the measured data.

$$
T_{s}(Y)=T_{\infty}+\left[T_{s}(0)-T_{\infty}\right](\exp -\beta Y),
$$

where $\beta$ is a constant depending on location and season, and $T_{\infty}$ is the temperature at infinite depth. Normalization of (14) in conjunction with (15) will give

$$
\mathrm{d} t / \mathrm{d} y-\varepsilon t=-\varepsilon t_{s}
$$

where

$$
\begin{aligned}
t & \equiv \frac{T_{s}(0)-T(Y)}{T_{s}(0)-T_{s}(H)} \\
t_{s} & \equiv \frac{T_{s}(0)-T_{s}(Y)}{T_{s}(0)-T_{s}(H)}=E[1-\exp (-\beta H y)], \\
E & =\frac{T_{s}(0)-T_{\infty}}{T_{s}(0)-T_{s}(H)} \\
y & \equiv Y / H \\
\varepsilon & \equiv 4 L U / k_{f} \mathrm{Pe}, \\
\mathrm{Pe} & =\text { Peclet number }=\text { PrRe. }
\end{aligned}
$$

Solving (16) with boundary condition, $t(1)=1$, we obtain the fluid temperature distribution inside the pipe,

$t(y)=E-\frac{\varepsilon E \exp (-\Gamma y)}{\Gamma+\varepsilon}+\left[1-E+\frac{\varepsilon E \exp (-\Gamma)}{\Gamma+\varepsilon}\right] \exp [\varepsilon(y-1)]$,

where $\Gamma \equiv \beta H$. From (17), the outlet temperature of cold deep seawater drawn through a straight pipeline can be determined:

$$
t(0) \equiv \chi_{0}=E+(1-E) \exp (-\varepsilon)-\frac{\varepsilon E}{\Gamma+\varepsilon}\{1-\exp [-(\Gamma+\varepsilon)]\} .
$$

The unity value of $t_{0}$ represents no heating loss during pumping which takes place in perfectly insulated pipe, i.e. $U=0$, or $\varepsilon=0$. The value of $t_{0}$ is always less than 1 and thus indicates the amount of coldness of the deep seawater remaining after pumping out of the sea surface. Therefore the heating loss during pumping can be readily examined from the values of $t_{0}$. The factor $\varepsilon$ has the physical significance of the overall heat transfer across 
the pipe wall, and $\Gamma$ represents the effect of seawater temperature distribution on the heating loss. $\beta$ or $\Gamma$ is zero for a constant-temperature sea and approsches infinity for an abrupt change of temperature at the sea surface. Equation (18) is plotted in Fig. 3 to show the variation of $t_{0}$ with $\Gamma$ and $\varepsilon$.

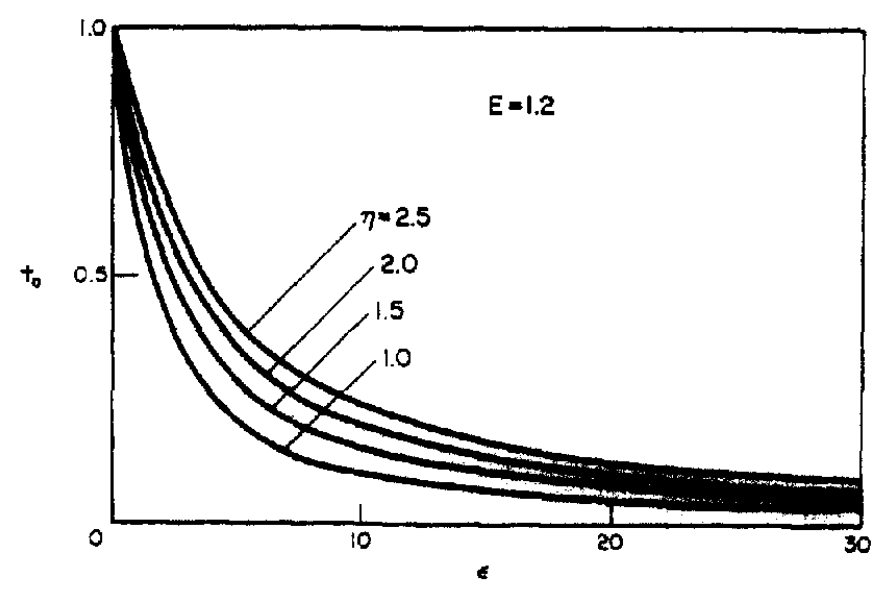

FIG. 3. Deep seawater temperature at the outlet of the pipeline.

\section{COOLING OF NUCLEAR POWER PLAN T BY COLD DEEP SEAWATER}

In drawing cold deep seawater through a long pipeline, power is needed to overcome the friction and density-gradient losses, and the seawnter is warmed up by the warmer seawater outside the pipe all the way up to the sea surface. The possibility of using this warmed deep senwater as a cooling medium for a power plant dopeads upon the flowrate and pipeline deaigns such as length, diameter and insulation material of the pipe.

Consider a power plant orifinally cooled by surface senwater. According to the priaciple of thermodynamics, the replacement of cold deep seawater as coolant would reduce the condensation temperature of the power cycle, thus promoting thermal efficiency. As a first order approximation, one can assume that the thermal efficiency $\eta$ is proportional to the Carnot efficiency, i.e.

$$
\eta=\dot{W}_{\mathrm{mol}} / Q_{H} \propto 1-T_{\mathrm{C}} / T_{H}
$$

where $\dot{W}_{m}$ is the net power output of the power plant, $Q_{H}$ is the heat added to the boiler, $T_{C}$ is the condensation temperature, and $T_{H}$ is the boiling temperature. For simplicity, we assume that replacement with cold deep seawater as coolant will lower the condentation temperature by an amount of $T_{s}-T_{0}$, where $T_{t}$ is the surface seawater temperature, and $T_{0}$ is the deep seawater temperature at the outlet of the pipeline which can be evaluated by (18). The new condensation temperature $T_{C}^{\text {t }}$ then becomes

$$
T_{C}^{*}=T_{C}-\left(T_{s 0}-T_{0}\right)
$$


and the new thermal efficiency $\eta *$ becomes

$$
\eta^{*}=\dot{W}_{\text {net }}^{*} / Q_{H} \propto 1-T_{c}^{*} / T_{H}
$$

where $\dot{W}_{\text {ne }}^{*}$ is the new output power. Here, we also assume that the new higher output power can be delivered by a properly renewed turbine generator and all the components in the power plant can be reconstructed to meet the power output increase due to lowering condensation temperature. Therefore, the ratio of the power outputs will be

$$
\dot{W}_{\text {net }}^{*} / \dot{W}_{\text {net }}=1+\left(T_{s 0}-T_{0}\right) /\left(T_{H}-T_{C}\right)
$$

The net power gain by deep seawater coolant $G$ is therefore the difference between the power increase, $\dot{W}_{\text {net }}^{*}-\dot{W}_{\text {not, }}$ and the required deep seawater pumping power, $\dot{W}_{p}$,

$$
G=\left(\dot{W}_{\text {net }}^{*}-\dot{W}_{\text {net }}\right)-\dot{W}_{p}
$$

Substituting (22) into (23), we obtain

$$
G=\left[\left(T_{s 0}-T_{0}\right) /\left(T_{H}-T_{C}\right)\right] \dot{W}_{\text {pot }}-\dot{W}_{p}
$$

From (24), it can be seen that the net power gain by deep seawater cooling is dependent on the outlet temperature of the pipeline, the highest and the lowest temperatures, the net power output in the original power cycle, and the pumping power consumed in drawing deep seawater through the pipeline. Associated with the previous pumping power calculations, the net power gain can be evaluated.

\section{APPLICATIONS FOR MARICULTURE AND NUCLEAR POWER PLANT COOLING ON THE EASTERN COAST OF TAIWAN}

Taiwan is a small spindle-shaped island located in the western Pacific ocean. Preliminary investigaions indicate that the east coast of Taiwan is very similar to the Virgin Islands in both meteorological and oceanographical conditions. Therefore, the applications of cold deep seawater on the eastern coast for mariculture and nuclear power plant cooling will be investigated according to the previous modeling.

Two locations on the eastern coast are selected for the present study. The results of the physical oceanographic measurements in the spring season at these locations are shown in Tables 1 and 2 (National Taiwan University, 1977). The seawater temperature distributions are first least-square fitted to (15) with the assumption that $T_{\infty}$ is $1^{\circ} \mathrm{C}$. The values of the exponents $\beta$ are then determined and shown in Figs 4 and 5 . The density distributions are plotted in Fig. 6.

\subsection{Pumping power evaluations}

From (10) and (11), we know that the pumping power required for drawing deep seawater through a pipeline depends on the intake level, the total length and diameter of the pipeline, and the flowrate. The simulation is performed for pipe diameters $D=7.5,10$, $15,50,100$, and $150 \mathrm{~cm}$. The first four diameters are suitable for mariculture applications 
Table 1. Ocranographic data at station $30\left(22^{\circ} 45\right.$ ' , $121^{\circ} 17^{\prime} \mathrm{E}$, OFTHONE DISTANCE: $19 \mathrm{~km}$ )

\begin{tabular}{ccc}
\hline $\begin{array}{c}\text { Depth } \\
\mathrm{m}\end{array}$ & $\begin{array}{c}\text { Temperature } \\
{ }^{\circ} \mathrm{C}\end{array}$ & $\begin{array}{c}\text { Deraity } \\
\mathrm{g} / \mathrm{l}\end{array}$ \\
\hline 0 & 27.2 & 1022.1 \\
10 & 26.9 & 1022.3 \\
20 & 25.9 & 1022.6 \\
30 & 25.8 & 1022.6 \\
50 & 24.4 & 1023.1 \\
75 & 23.5 & 1023.4 \\
100 & 21.0 & 1024.1 \\
125 & 20.4 & 1024.3 \\
150 & 18.8 & 1024.7 \\
200 & 15.9 & 1025.4 \\
250 & 14.3 & 1025.7 \\
300 & 12.8 & 1025.9 \\
400 & 10.3 & 1026.3 \\
500 & 8.5 & 1026.6 \\
600 & 7.2 & 1026.8 \\
700 & 6.3 & 1027.0 \\
800 & 5.6 & 1027.1 \\
1000 & 4.0 & 1027.2 \\
\hline
\end{tabular}

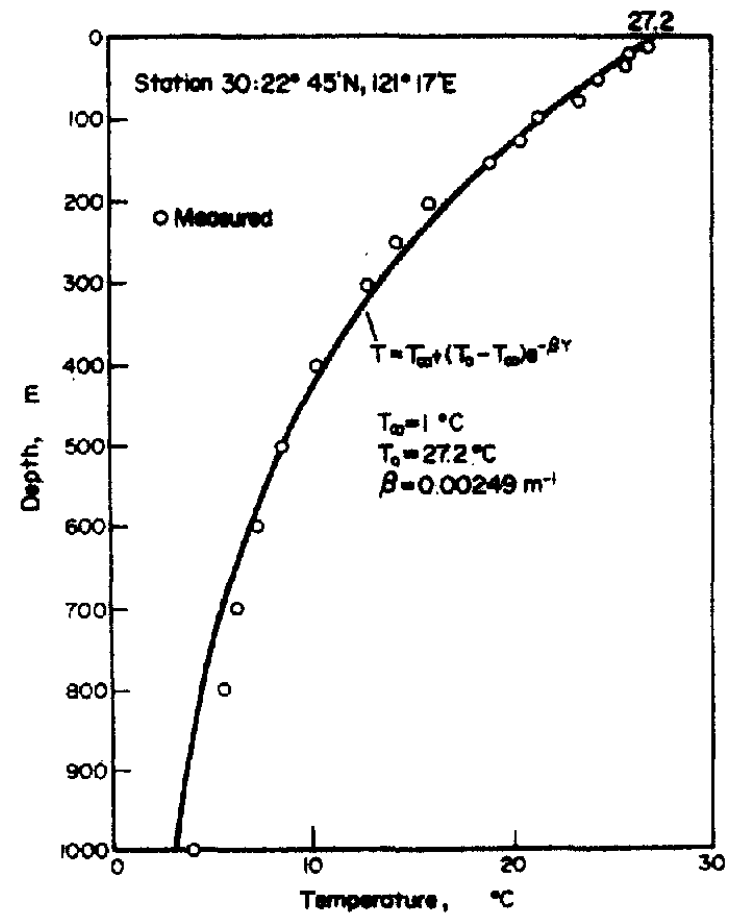

F10. 4. Temperature diatribution at Station 30. 


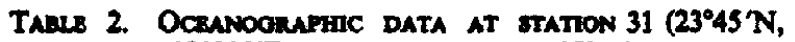

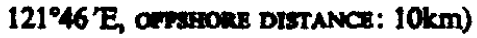

\begin{tabular}{ccc}
\hline $\begin{array}{c}\text { Depth } \\
(\mathrm{m})\end{array}$ & $\begin{array}{c}\text { Temperuture } \\
\left({ }^{\circ} \mathrm{C}\right)\end{array}$ & $\begin{array}{c}\text { Density } \\
(\mathrm{g} / \mathrm{l})\end{array}$ \\
\hline 0 & 25.5 & 1022.9 \\
10 & 25.3 & 1023.0 \\
20 & 25.2 & 1023.1 \\
30 & 24.7 & 1023.2 \\
50 & 23.9 & 1023.5 \\
75 & 22.3 & 1024.0 \\
100 & 20.3 & 1024.6 \\
125 & 19.0 & 1024.9 \\
150 & 17.7 & 1025.2 \\
200 & 15.6 & 1025.7 \\
250 & 14.1 & 1025.9 \\
300 & 12.9 & 1026.1 \\
400 & 10.8 & 1026.6 \\
500 & 8.5 & 1026.9 \\
600 & 7.0 & 1027.0 \\
700 & 6.0 & 1027.2 \\
800 & 5.3 & 1027.2 \\
1000 & 4.3 & 1027.4 \\
\hline
\end{tabular}

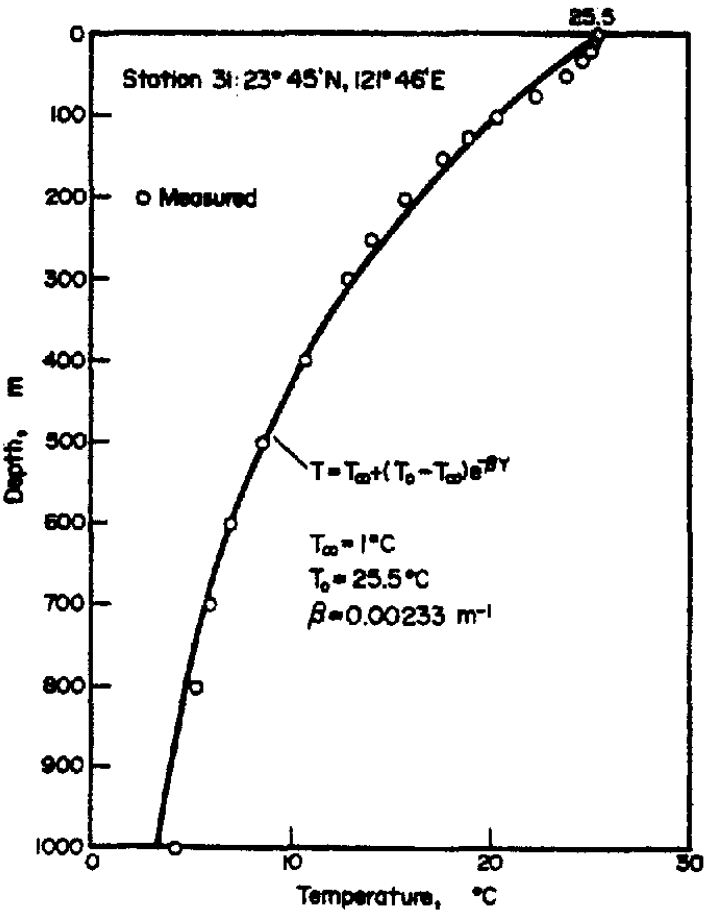

Fic. 5. Temperature distribution at Station 31. 


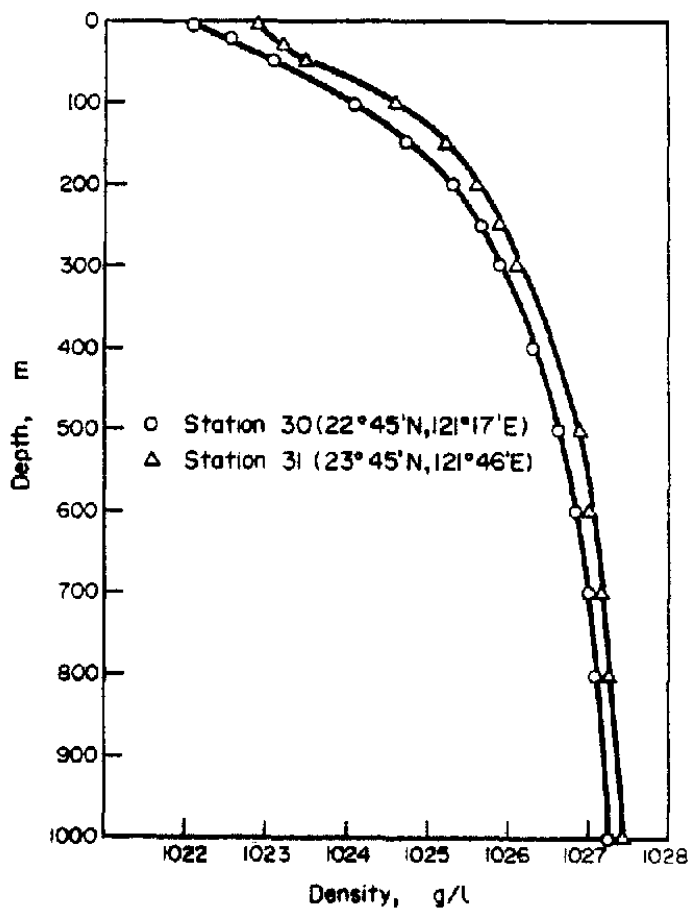

FIG. 6. Density distribution.

and the rest are suitable for power plant cooling. The intake levels $H$ are taken as 400,600 , 800 , and $1000 \mathrm{~m}$ for the present calculation. The results are shown in Figs 7 12.

It is seen that the required pumping power for each diameter is independent of the intake level at high flowrntes. This is due to the fact that the slopes of pipelines in the present simulations are smaller than 0.10 , thexefore the pumping power is, from (11), approximately independent of the intake level. For low flowrates, the density-gradienthead loss becomes dominant compared with the frictional loss, and therefore the pumping power depends upon the intake level.

The calculations show that the pumping power is less than $100 \mathrm{~kW}$ for pipe diameters smaller than $15 \mathrm{~cm}$ and mass flowrates lower than 100 ton/h which is just in the range of mariculture applications. To reduce the pumping power in nuclear power plant cooling applications the pipeline diameter has to be larger than $50 \mathrm{~cm}$.

\subsection{Heating loss during pumping}

Equation (18) gives the outlet temperature of cold deep seawater through a pipeline if the overall heat transfer coefficient $U$ is determined. In general, the overall heat transfer coefficient can be evaluated by the following equation:

$$
U=1 /\left[1 / h_{l}+\ln \left(r_{0} / r_{1}\right) / 2 \pi k_{p}+1 / h_{0}\right]
$$


where

$h_{i}=$ convective heat transfer coefficient at pipe inner wall,

$h_{0}=$ convective heat transfer coefficient at pipe outer wall,

$r_{i}=$ inside radius of pipe,

$r_{0}=$ outside radius of pipe,

$k_{p}=$ thermal conductivity of pipe material.

The convective heat transfer coefficient at the inner wall can be evaluated by the equation for forced-convection (Dittus and Boelter, 1930),

$$
\mathrm{Nu}_{i}= \begin{cases}4.36, & \mathrm{Re}<2100 \\ 0.023 \mathrm{Re}^{0.8 \mathrm{Pr}^{0.4},} & 2100<\mathrm{Re}\end{cases}
$$

where $\mathrm{Nu}$ is the Nusselt number defined as $h_{i} D / k_{f}$. The heat transfer at the outside wall is determined by the tidal current which varies from location to location in the sea and is very difficult to measure. However, the pipeline is usually laid out along the sea bathymetry so that the effect of tidal currents can be neglected and the heat transfer at the outside wall is dominated by free convection. Since the slope of the pipeline is in general very small, the following empirical equation for free convection on a horizontal cylinder can be approximated to evaluate the heat transfer coefficient at the outside pipe surface (Churchill and Chu, 1975):

$$
\mathrm{Nu}_{0}^{1 / 2}=0.60+0.387\left\{\frac{\mathrm{GrPr}}{\left[1+(0.559 / \mathrm{PT})^{0 / 16}\right]^{1010}}\right\}^{1 / 0},
$$

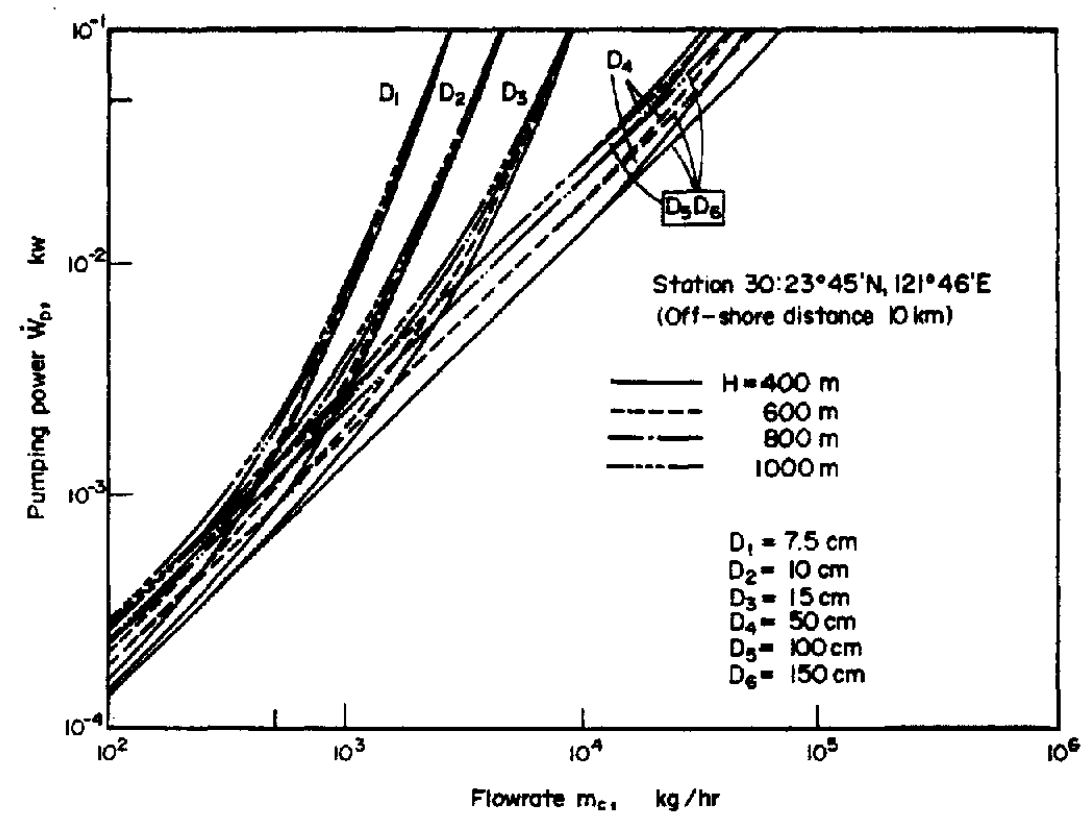

FIG. 7. Pumping power vs mass flowrate. 
for $10^{-1}<\mathrm{GrPr}<10^{12}$, where $\mathrm{Gr}=$ Grashof number based on film temperature, and $\mathrm{Nu}_{0}$ is the Nusaelt number defined as $h_{0} D_{a} / k_{f}$.

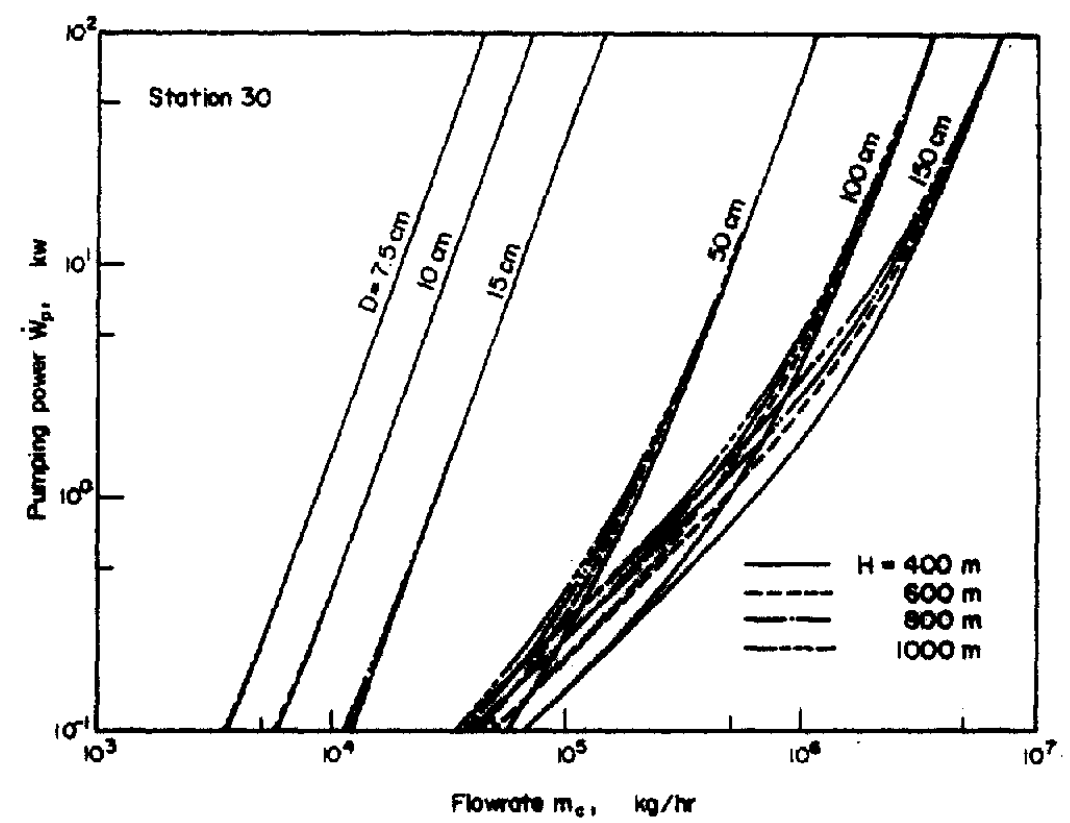

Fio. 8. Pumping power ve mass flowrate.

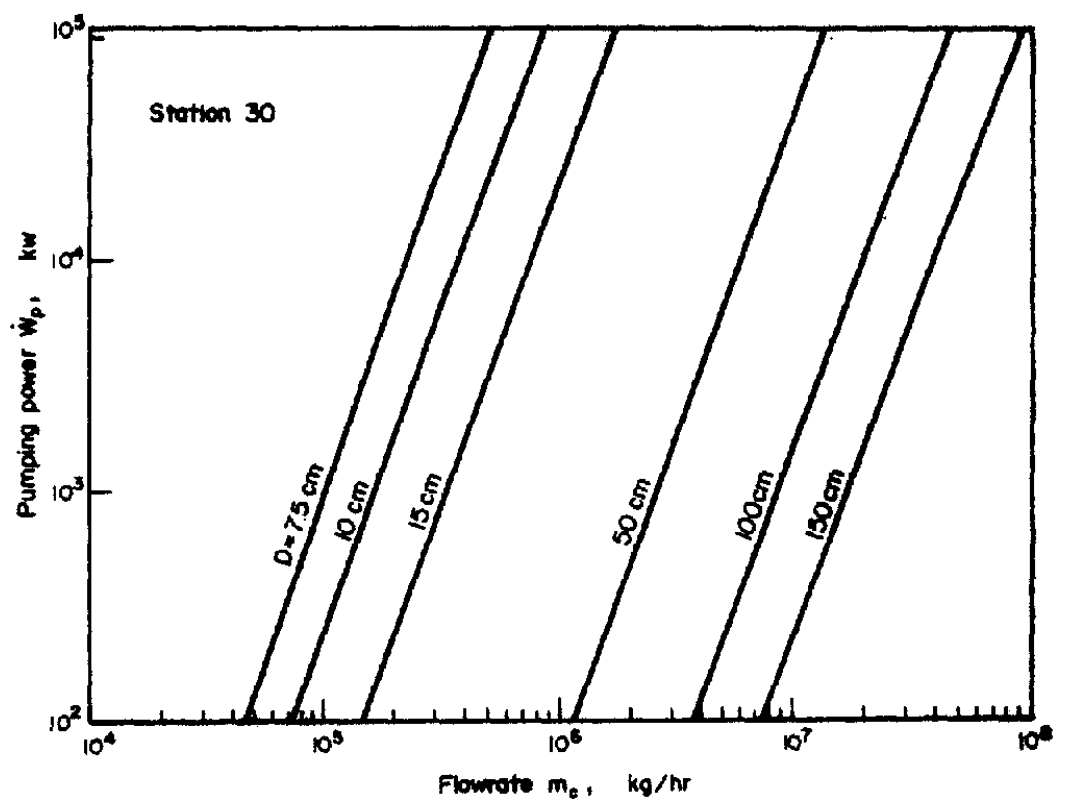

Fro. 9. Pumpias power vs man flowrate. 
If the pipe is not well-insulated, e.g. bare metal pipe, the thermal resistance through the wall is negligible compared with the convective heat transfer, and therefore

$$
U \approx h_{p} h_{0} /\left(h_{i}+h_{\mathrm{q}}\right)
$$

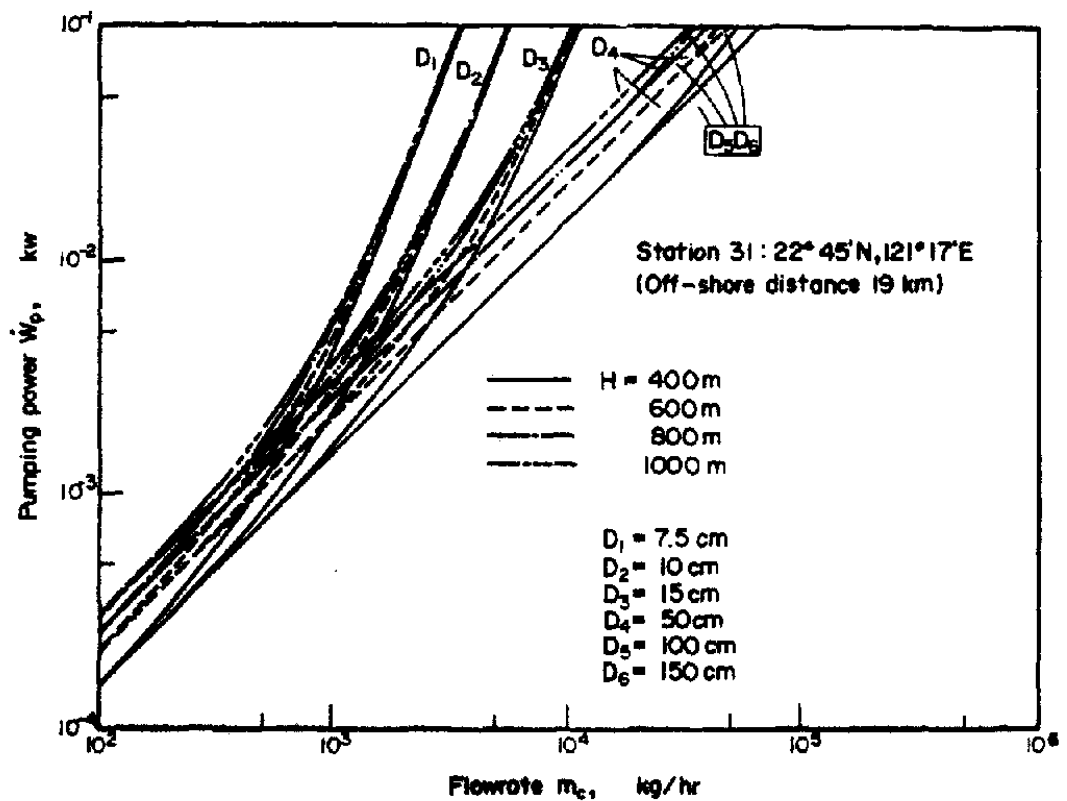

Fic. 10. Pumping power vs mass flowrate.

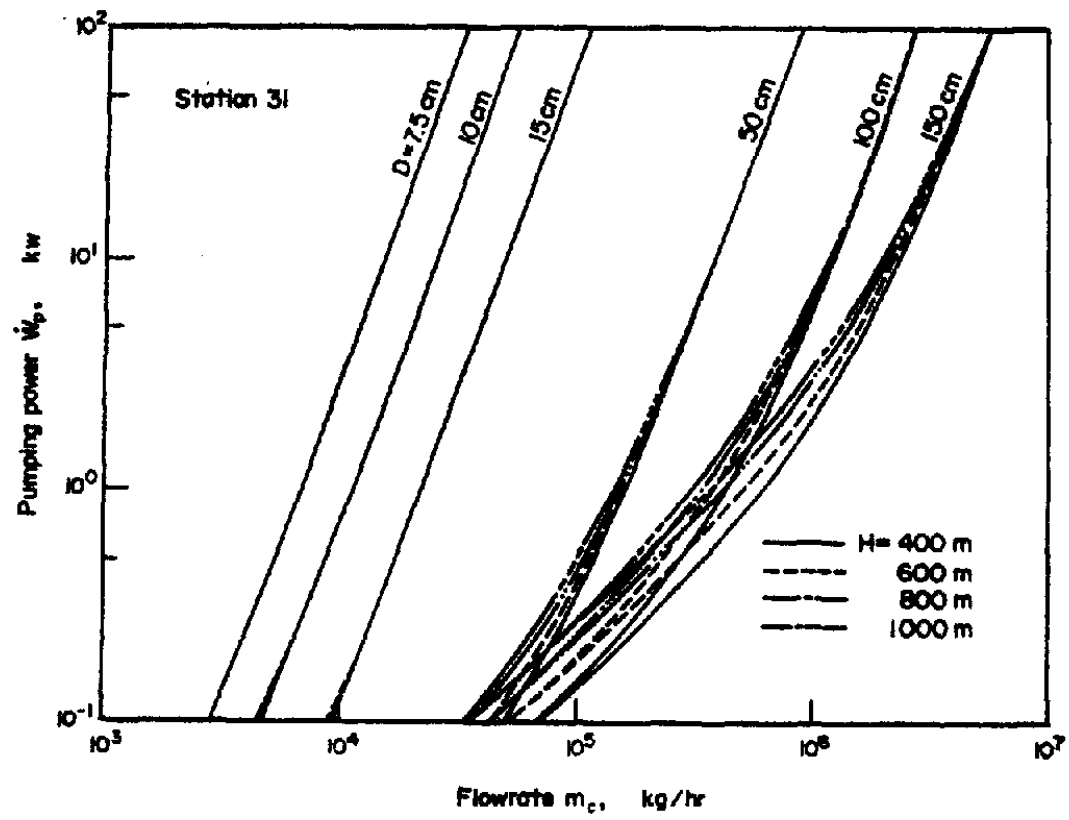

Fro. 11. Pumping power vs mass flowrate. 


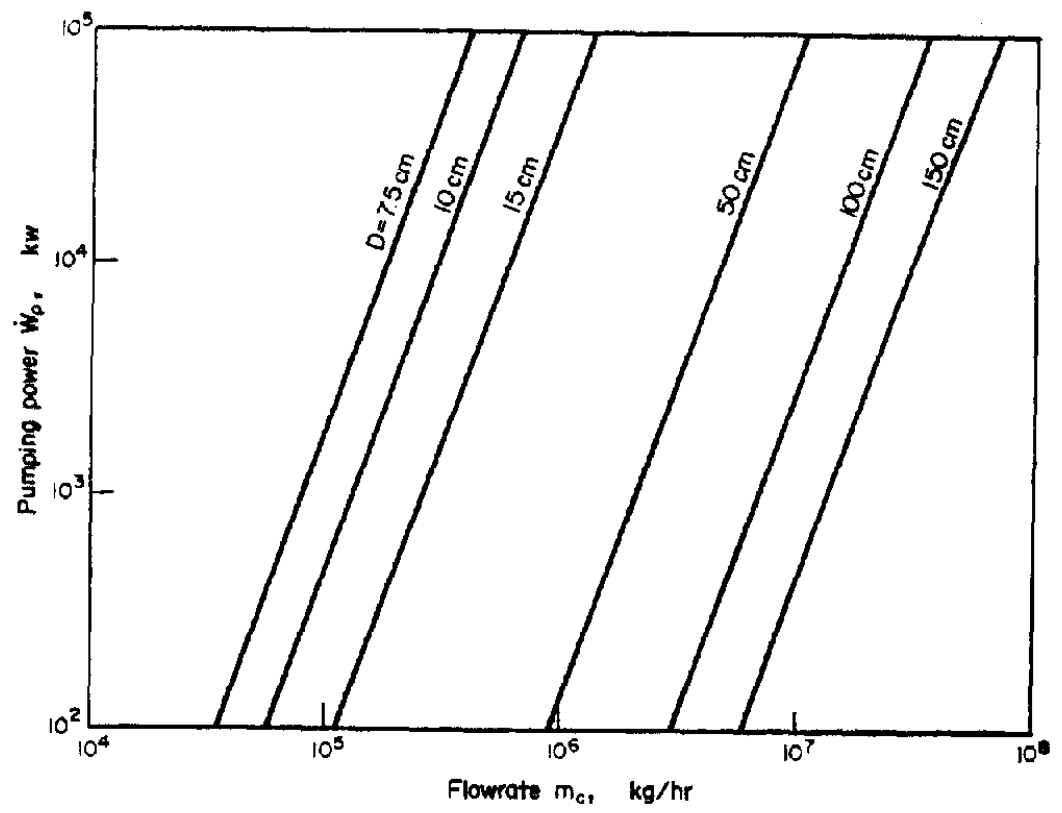

Frg. 12. Pumping power vs mass flowrate.

Associated with the previous data, the temperature rise is calculated for pipe diameter $D=7.5,10,15,50,100$ and $150 \mathrm{~cm}$, and the intake level $H=800$ and $1000 \mathrm{~m}$. The results are shown in Figs 13 and 14.

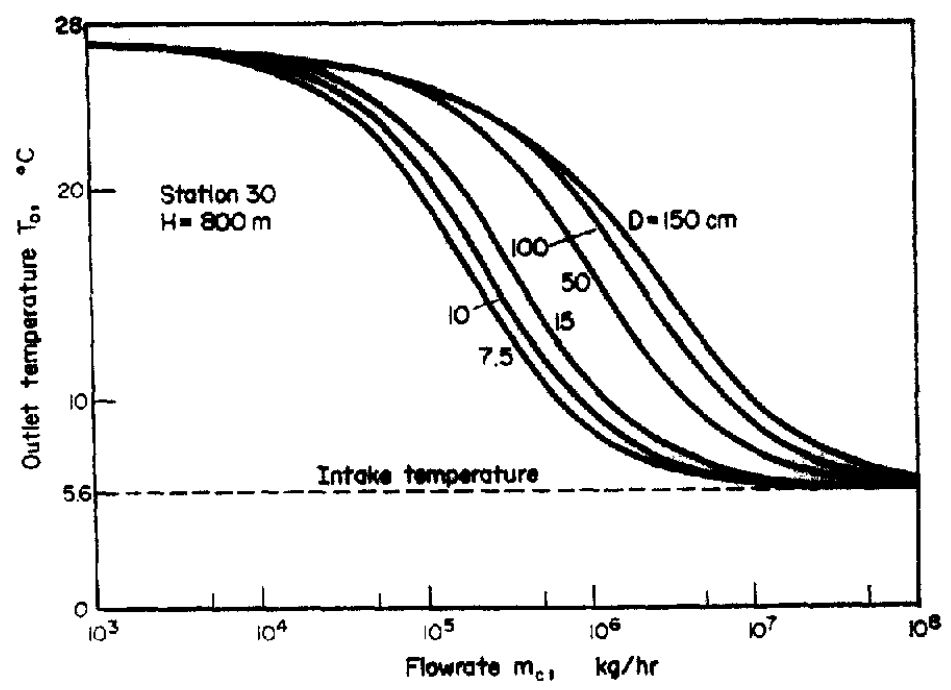

FiG. 13. Outlet temperature vs mass flowrate. 


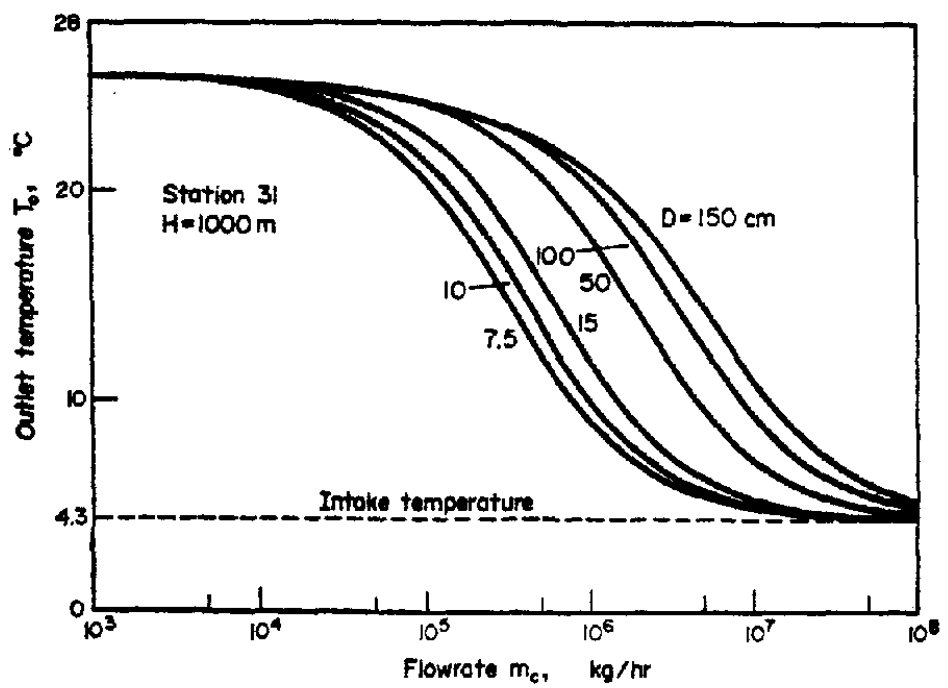

Fig. 14. Outlet temperature vs mass flowrate.

For a well-inculated pipe, the heat resistance through the insulation layer is so high that the overall heat transfer coefficient $U$ approaches zero, and the outlet temperature of the drep seawnter is the same as the intake temperature as shown in Figs 13 and 14. It is seen that the cold seawater will be considerably warmed up as the flowrate is too small. High fiowrate could reduce the heating loas, but the pumping power would be too large to be applicable.

\subsection{Fassibility of muclear power plant cooling applications}

Using (24) and previous simulation results for pumping power and heating loss, the feasibility of nuclear power plant cooling applications can be assessed. The nuclear power plant selected for the present simulation is the unit now installed at Chin Shan in northern Taiwan. This power plant now delivers a net output $\dot{W}_{\text {net }}$ of $635 \mathrm{MW}$ at the highest cycle temperature $T_{B}$ of $288^{\circ} \mathrm{C}$, the condensation temperature $T_{C}$ of $47^{\circ} \mathrm{C}$, and the cooling water flowrate $m_{c}$ of $3.3 \times 10^{7} \mathrm{~kg} / \mathrm{hr}$.

The net power gain by deep seawater cooling $G$ is calculated for two limiting cases: well-insulated pipeline and bare metal pipeline. Tables 3 and 4 show the variations of net gain with pipe diameter and intake level. It can be seen that a reasonable positive gain can be obtained only for pipes with diameters larger than $150 \mathrm{~cm}$ and intake levels deeper than $400 \mathrm{~m}$.

\section{GRAVITATIONAL FORCE-INDUCED FLOW SYSTEM}

To eliminate the maintenance problems of the pumping facilities, a new piping arrangement is proposed and examined. This pipeline is similar to the first kind except that the outlet of the pipeline is open to a deep ground-hole at the seashore, thus maintaining an elevation between the sea surface and the outlet of the pipe to induce a gravitational driving force to draw up deep seawater (see Fig. 15). 


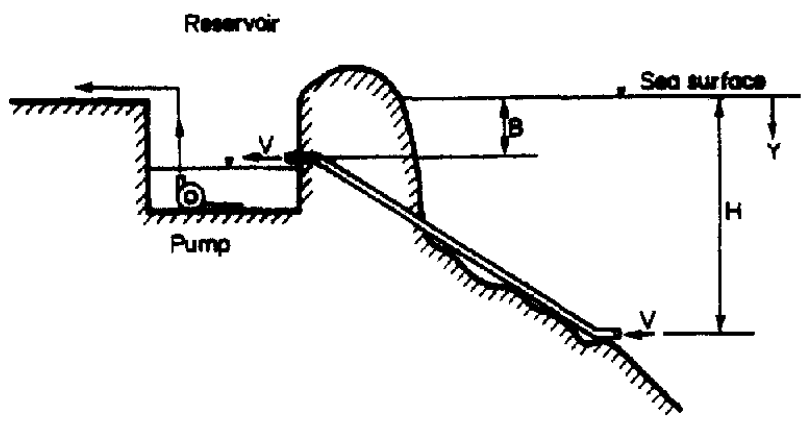

Fio. 15. Gravitational force-induced fiow system.

Applying the Bernoulli equation, (1), to the modified pipeline model with the same conditions, the momentum equation can be derived:

$$
\begin{cases}Z-r+32 n \operatorname{Re}=0 & \operatorname{Re}<2100 \\ Z-r+0.1582 n \operatorname{Re}^{7 / 4}=0, & 2100<\operatorname{Re}<20,000 \\ Z-r+0.092 n \operatorname{Re}^{916}=0, & 20,000<\operatorname{Re}<10^{7}\end{cases}
$$

The induced flowrate can thus be determined in terms of $r, Z$ and $n$. Since the enarey equation remains the same as in the previous case, the outlet temperature $t_{0} \operatorname{cas}$ be derived:

$$
t_{0}=E-\frac{\varepsilon E \exp (-\Gamma r)}{\Gamma+\varepsilon}+\left[1-E+\frac{\varepsilon E \exp (-\Gamma)}{\Gamma+\varepsilon}\right] \exp [\varepsilon(r-1)]
$$

\begin{tabular}{|c|c|c|c|c|}
\hline \multicolumn{5}{|c|}{ Bare matal pipe } \\
\hline$D(\mathrm{~cm})$ & 400 & 600 & 800 & 1000 \\
\hline $\begin{array}{l}7.5 \\
10 \\
15 \\
50 \\
100 \\
150\end{array}$ & $\begin{array}{l}-1.1850 \times 10^{7 M W} \\
-2.9787 \times 10^{\circ} \\
-4.2540 \times 10^{6} \\
-1.2756 \times 10^{3} \\
-8.9488 \\
30.294\end{array}$ & $\begin{array}{l}-1.1852 \times 10^{\circ} \mathrm{MW} \\
-2.9787 \times 10^{\circ} \\
-4.2540 \times 10^{\circ} \\
-1.2644 \times 10^{\circ} \\
-1.6730 \\
37.580\end{array}$ & $\begin{array}{l}-1.1864 \times 10^{9} \mathrm{MW} \\
-2.9816 \times 10^{\circ} \\
-4.2582 \times 10^{6} \\
-1.2655 \times 10^{\circ} \\
2.5100 \\
41.879\end{array}$ & $\begin{array}{l}-1.1881 \times 10^{10 \mathrm{MW}} \\
-2.9965 \times 10^{0} \\
-4.2610 \times 10^{\circ} \\
-1.2634 \times 10^{\circ} \\
6.3990 \\
45.833\end{array}$ \\
\hline \multicolumn{5}{|c|}{ Well-insulated pipe } \\
\hline$D(\mathrm{~cm})$ & 400 & 600 & 800 & 1000 \\
\hline $\begin{array}{l}7.5 \\
10 \\
15 \\
50 \\
100 \\
150\end{array}$ & $\begin{array}{l}-1.1851 \times 10^{\circ} \mathrm{MW} \\
-2.9767 \times 10^{\circ} \\
-4.2540 \times 10^{5} \\
-1.2741 \times 10^{0} \\
-6.1697 \\
34.300\end{array}$ & $\begin{array}{c}-1.1852 \times 10^{\circ} \mathrm{MW} \\
-2.9787 \times 10^{\circ} \\
-4.2400 \times 10^{4} \\
-1.2699 \times 10^{3} \\
1.1760 \\
41.647\end{array}$ & $\begin{array}{l}-1.1864 \times 10^{1} \mathrm{MW} \\
-2.9916 \times 10^{\circ} \\
-4.2582 \times 10^{\circ} \\
-1.2641 \times 10^{\circ} \\
5.1560 \\
45.667\end{array}$ & $\begin{array}{l}-1.1881 \times 10^{9} \mathrm{MW} \\
-2.9065 \times 10^{\circ} \\
-4.2500 \times 10^{\circ} \\
-1.2690 \times 10^{\circ} \\
9.0150 \\
49.588\end{array}$ \\
\hline
\end{tabular}

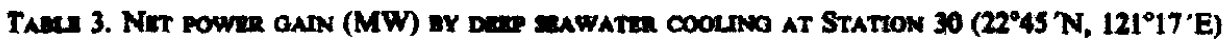


Table 4. Net power gain (MW) by deEp seawater cooling at Station $31\left(23^{\circ} 45^{\prime} \mathrm{N}, 1^{\circ} 1^{\circ} 46^{\prime} \mathrm{E}\right)$

\begin{tabular}{|c|c|c|c|c|c|}
\hline \multirow[b]{2}{*}{$D(\mathrm{~cm})$} & \multicolumn{4}{|c|}{ Bare metal pipe } & \multirow[b]{2}{*}{1000} \\
\hline & & 400 & 600 & 800 & \\
\hline $\begin{array}{l}7.5 \\
10 \\
15 \\
50 \\
100 \\
150\end{array}$ & $\begin{array}{c}-2.2493 \\
-5.6539 \\
-8.0756 \\
-2.4629 \\
-58.205 \\
16.893\end{array}$ & $\begin{array}{l}\times 10^{2} \mathrm{MW} \\
\times 10^{8} \\
\times 10^{8} \\
\times 10^{3}\end{array}$ & $\begin{array}{l}-2.2487 \times 10^{7} \mathrm{MW} \\
-5.6513 \times 10^{\circ} \\
-8.0705 \times 10^{5} \\
-2.4533 \times 10^{3} \\
-49.673 \\
25.077\end{array}$ & $\begin{array}{l}-2.2477 \times 10^{1} \mathrm{MW} \\
-5.6503 \times 10^{6} \\
-8.0698 \times 10^{8} \\
-2.4483 \times 10^{3} \\
-45.273 \\
29.515\end{array}$ & $\begin{array}{c}-2.2487 \times 10^{9} \mathrm{MW} \\
-5.6516 \times 10^{4} \\
-8.0705 \times 10^{5} \\
-2.4466 \times 10^{9} \\
-42.641 \\
32.329\end{array}$ \\
\hline & & & Well-insulated pipe & & \\
\hline$D(\mathrm{~cm})$ & & 400 & 600 & 800 & 1000 \\
\hline $\begin{array}{l}7.5 \\
10 \\
15 \\
50 \\
100 \\
150\end{array}$ & $\begin{array}{r}-2.2493 \\
-5.6539 \\
-8.0756 \\
-2.4609 \\
-53.884 \\
22.919\end{array}$ & $\begin{array}{l}\times 10^{7} \mathrm{MW} \\
\times 10^{8} \\
\times 10^{5} \\
\times 10^{3}\end{array}$ & $\begin{array}{l}-2.2487 \times 10^{7} \mathrm{MW} \\
-5.6513 \times 10^{8} \\
-8.0705 \times 10^{8} \\
-2.4506 \times 10^{2} \\
-44.598 \\
32.182\end{array}$ & $\begin{array}{c}-2.2477 \times 10^{9} \mathrm{MW} \\
-5.6503 \times 10^{1} \\
-8.0698 \times 10^{5} \\
-2.4456 \times 10^{3} \\
-40.418 \\
36.349\end{array}$ & $\begin{array}{l}-2.2487 \times 10^{7} \mathrm{MW} \\
-5.6516 \times 10^{8} \\
-8.0705 \times 10^{5} \\
-2.4439 \times 10^{8} \\
-38.204 \\
38.576\end{array}$ \\
\hline
\end{tabular}

where $r=B / H$. A calculation was carried out at Station 30 to check the induced mass flowrate and the outlet temperature. Figure 16 presents the variations of induced flowrate with the ground-hole depth and the intake level for each pipe diameter. Figures 17 and 18 show the outlet temperature of the deep seawater. It is seen that, to obtain a high flowrate for nuclear power plant cooling, the diameter of the pipe should be larger than $150 \mathrm{~cm}$ and the depth of the ground-hole should be deeper than about $75 \mathrm{~m}$. This will not, in practice, be economically feasible. However, for low flowrate applications such as mariculture, the use of a gravitational flow system is possible as the required ground-hole will not be too deep.

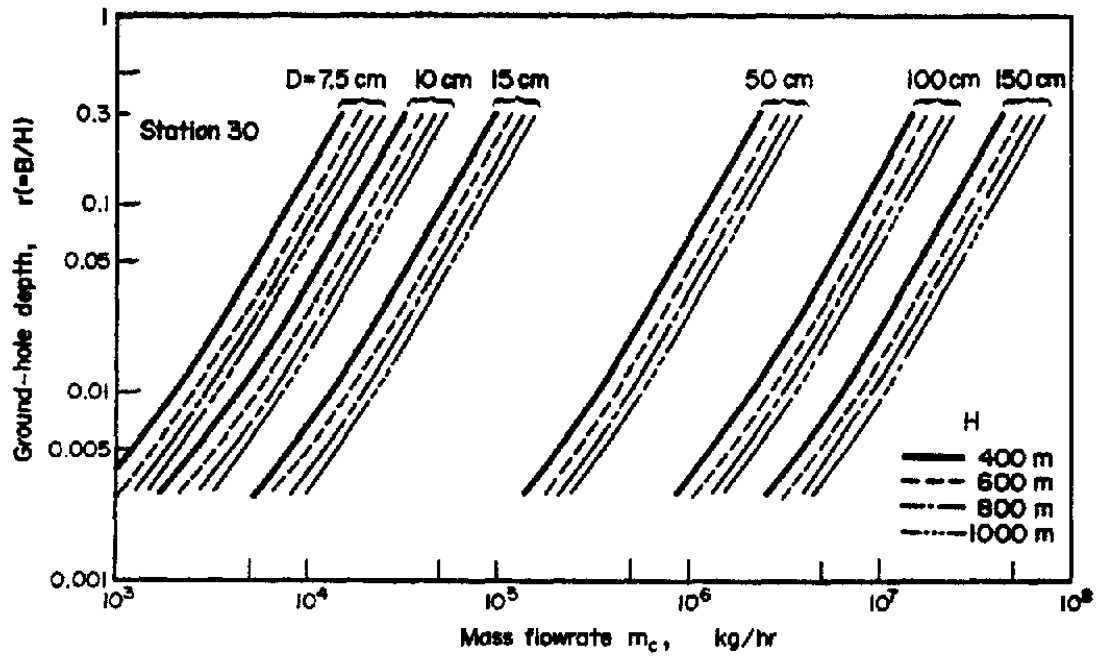

Fig. 16. Induced fiowrate vs hole depth. 


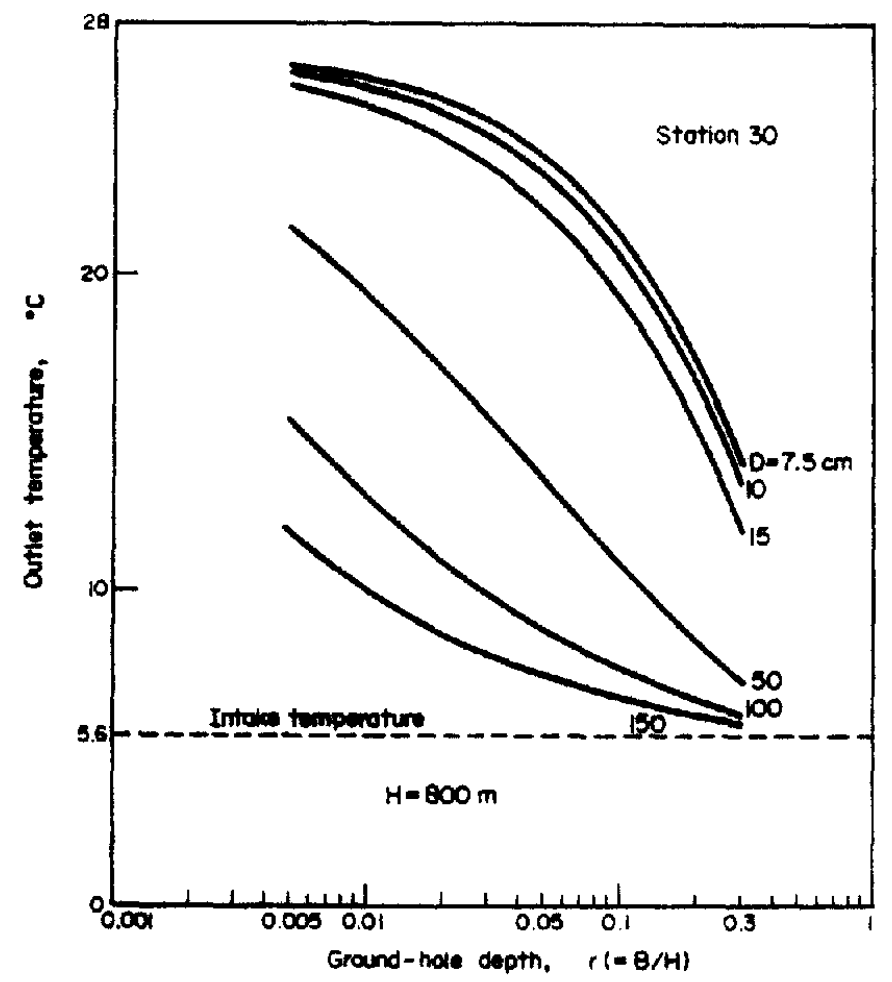

FIG. 17. Outlet temperature vs holo depth for gravitational system.

\section{DISCUSSION AND CONCLUSION}

A simple theoretical model is developed to assess the technical feasibility of pumping cold deep nutrient-rich seawater for mariculture, and for nuclear power plant cooling. The model assumes that the pipeline is straight and laid out directly to the intake level in the deep sea region. However, the bathymetrical map of Taiwan shows that there is a very narrow shelf along the east coast. Generally the continental slope drops off to $1000 \mathrm{~m}$ within $10 \mathrm{~km}$ from the coast. At several points off the coast, the $1000 \mathrm{~m}$ contour is even closer, within $2 \mathrm{~km}$. Therefore a underwater straight pipeline cannot be constructed to reach the deep sea region. Instead a stepwise pipeline, as shown in Fig. 19, is more likely to be built in practical applications. Thus the previous calculation models should be modified by successive stepwise calculations using equations of similar form. Under these conditions, the pumping work equation becomes, from (1),

$$
W_{p}=\sum_{i=1}^{n}\left[g \Delta h_{i}+\int_{L_{i}} \mathrm{~d} P / \rho_{i}+f_{i}\left(L_{l} / R_{h}\right)_{l} v^{2} / 2+e_{v i} v_{i} 2 / 2\right]
$$

and the temperature variation at the ith section becomes

$$
\mathrm{d} T_{i} / \mathrm{d} X_{i}=\left(U_{l} \pi D_{l} / m_{c} C_{p}\right)\left(T_{s}-T_{i}\right), \quad i=1,2, \ldots,
$$




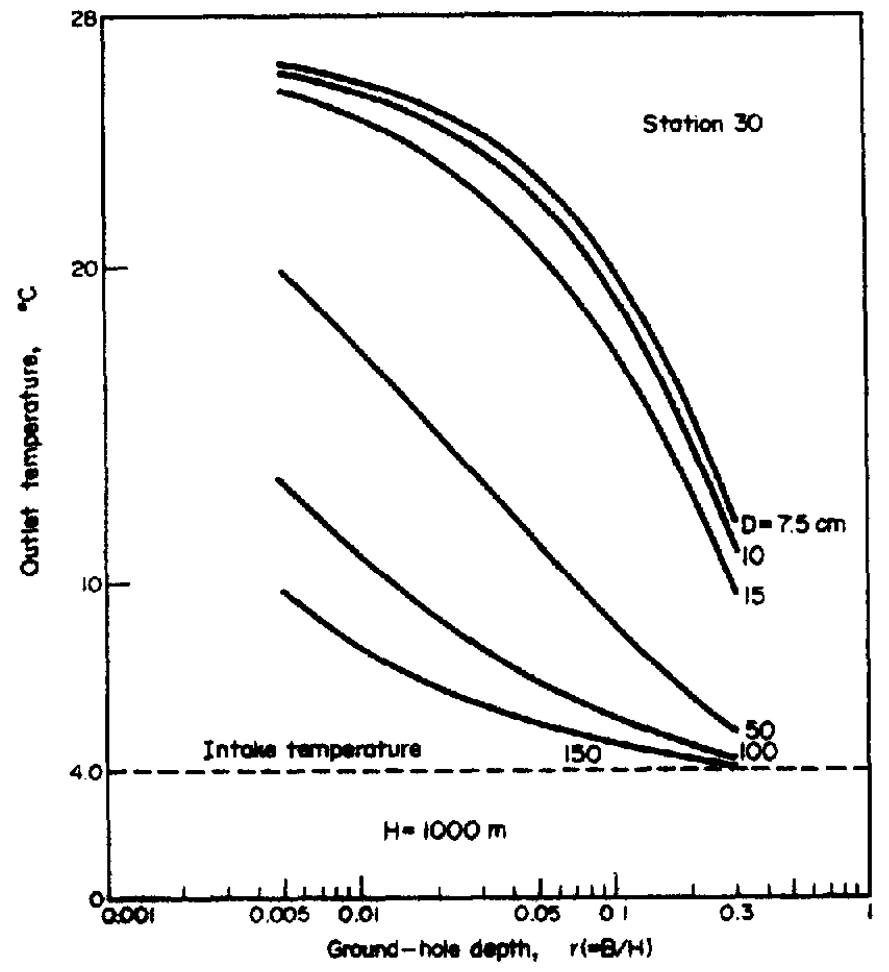

Fig. 18. Outlet temperature vs hole depth for gravitational system.

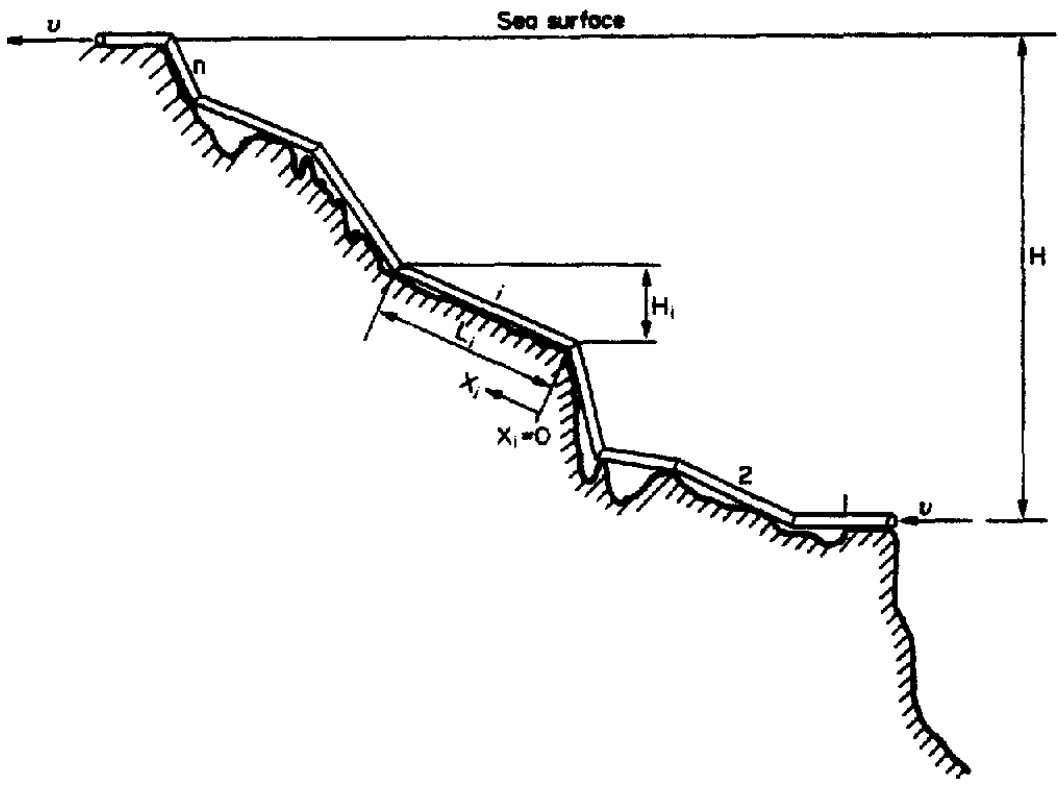

FIG. 19. Real piping configuration. 
with the boundary conditions:

$$
\begin{aligned}
& \text { for } i=1, T_{1}(0)=T_{H} \text { at } X_{1}=0 \\
& \rho_{1}(0)=\rho_{H} \text { at } X_{1}=0 \text {. }
\end{aligned}
$$

The detailed computations can be accurately achieved when the bathymetrical survey around the application site is completed.

The present analysis for two locations off the east coast of Taiwan and for two kinds of piping models leads to the following conclusions:

1. The pumping power required to draw seawater from the deep sea is always less than $100 \mathrm{~kW}$ (134 h.p.) for pipe diameters smaller than $15 \mathrm{~cm}$ and mass flowrates lower than $100 \mathrm{ton} / \mathrm{hr}$, which is suitable for mariculture application.

2. Replacing warm surface seawater by cold deep seawater as nuclear power plant coolant is technically feasible for pipes with diameters larger than $150 \mathrm{~cm}$ and intake levels deeper than $400 \mathrm{~m}$.

3. The gravitational force-induced flow system is not applicable for nuclear power plant cooling applications, but is applicable for mariculture applications.

4. For accurate predictions, the bathymetrical survey around the application site should be completed and the successive stepwise computation for a real pipeline geometry is required for design work.

5. For further practical applications, an economical feasibility investigation is necenary.

Acknowledpements-The author would like to thank Mr B. H. Chao for his assiatunce in numerical computation. The present work is partially supported by the National Science Council of the Republic of Ching.

\section{REFERENCES}

CHURCHIL, S. W. and CHU, H. H. S. 1975. Correlating equations for laminar and turbulent free convection from a horizontal cylinder. Int. J. Heat Mass Trensfer 18, 1049.

ClaUde, G. 1930. Powor from tropical seas. Mech. Ensurg 52, 1039.

Drtrus, F. W. and Bontek, L. M. K. 1940. Univ. Calif. Publs Engng 2, 443.

Grirws, O. M. 1971. The ocean as a renewable source of energy. J. Engng Ind. Trans. ASME 17, 897.

MOODY, D. F. 1944. Truns. Am. Soc. Mech. Engrs 66, 671.

NATIONAL TATWAN UnTVERstr. 1977. Oceanographic data of the sea surrowending Taiwan. Special Publn. No. 15.

OTnumb, D. F. 1976. Power, fresh water and food from the sea. Mech. Engng 27,

OTHMER, D. F. and Roels, O. A. 1973. Power, fresh water, and food from cold deep sea water. Science, N.Y. 182, 121.

Othuare, D. F. and Roets, O. A. 1974. Mar. Techol. Soc. J. 8, 40.

WATt, A. D., MATHEWS, F. S. and HATHAWAY, R. E. 1977. Open cycle ocean thermal energy conversion. $A$ preliminary engineering evaluation. U.S. Department of Energy, ALO/3723-76/3.

ZENER, C. 1977. Solar sea power. Mech. Engng. 27. 